\title{
CONTRIBUIÇÕES DA ECOLOGIA POLÍTICA PARA A DISCUSSÃO DA SEGURANÇA HÍDRICA
}

\section{CONTRIBUTIONS OF POLITICAL ECOLOGY TO THE DISCUSSION OF WATER SECURITY}

\author{
Beatriz Duarte Dunder ${ }^{(1)}$ \\ Mestre em Ciências pelo Programa de Pós Gradução em Ciência Ambiental (PROCAM USP) e Bacharel em Gestão \\ Ambiental pela Escola de Artes Ciências e Humanidades (EACH USP). \\ E-mail ${ }^{(1)}$ : beatrizdunder@gmail.com
}

\section{RESUMO}

O conceito de segurança hídrica tem ganhado destaque nos debates, visto a crescente vulnerabilidade da sociedade em relação à água, o que se tem visto, entretanto é uma serie de divergências em relação ao uso do conceito, e, além disso, uma captura do debate por setores que ignoraram as condicionantes políticas e sociais da (in)segurança hídrica. Nesse contexto o presente artigo tem como objetivo apresentar as contribuições do campo da ecologia política para a discussão sobre a segurança hídrica. Ainda que as pesquisas sobre água no campo da ecologia política raramente utilizem o termo "segurança hídrica", as análises e abordagens do campo contribuem para o tema, uma vez que exploram a desigualdades no acesso a água, com um enfoque nos modos como as relações sociais de poder combinados com fatores materiais e ecológicos moldam a forma como a água é distribuída.

\begin{abstract}
O The concept of water security has gained prominence in debates, given the growing vulnerability of society in relation to water, which has been seen, however, is a series of divergences regarding the use of the concept, and, in addition, a capture of debate by sectors that ignored the polítical and social constraints of water (in)security. In this context, this article aims to present the contributions of the field of polítical ecology to the discussion of water security. Although water research in the field of polítical ecology rarely uses the term "water security", analyzes and approaches from the field contribute to the theme, as they explore inequalities in access to water, with a focus on the ways in which relationships social power combined with material and ecological factors shape the way water is distributed.
\end{abstract}

Palavras-chave: Segurança Hídrica. Ecologia Política. Acesso à Água.

Key words: Water Security. Polítical Ecology. Access to Water.

\section{INTRODUÇÃO}

O conceito de segurança hídrica tem ganhado notoriedade em todo mundo por conta da crescente vulnerabilidade tanto da sociedade como dos ecossistemas em relação à água. São crescentes as ameaças aos sistemas de fornecimento de água por conta da contaminação e outros impactos nos ecossistemas aquáticos, causados pela atividade humana. Além das ameaças aos que já contam com o fornecimento de água, ainda existe um grande contingente populacional que sequer tem acesso seguro à água potável de forma sustentável (BAKKER, 2012).

Ainda sim, trata-se de um conceito que possui uma série de divergências quanto ao seu uso (COOK, BAKKER, 2011; LOFTUS, 2015). Já esteve bastante associado no passado a questões de segurança nacional no campo da geopolítica, mas recentemente o termo passou a ser empregado como uma questão de segurança humana, com ênfase na preocupação com as populações mais vulneráveis no que diz respeito ao acesso à água de forma segura (LOFTUS, 2015). 
O ponto de virada no uso do conceito segundo Cook e Bakker (2011) foi a publicação do documento preparado pela Global Water Partnership em 2000, intitulado "Towards Water Security: A Framework for action". Nesse documento a segurança hídrica é definida como:

"A segurança hídrica, em qualquer nível, desde o domicílio até a escala global, significa que cada pessoa tem acesso à água potável suficiente e a um custo acessível para levar uma vida limpa, saudável e produtiva, garantindo também que o ambiente natural seja protegido e aprimorado. Aqueles que usam e compartilham bacias hidrográficas e aquíferos devem gerenciar sua água de forma sustentável, equilibrando o uso da água para o desenvolvimento humano com a proteção de ecossistemas vitais e os serviços ecológicos que eles fornecem." (GLOBAL WATER PARTNERSHIP, 2000. Pág. 7, tradução nossa)

A partir dessa publicação o conceito passou a se popularizar em diversas áreas e em diferentes disciplinas. Cook e Bakker (2011) apontam que o conceito de segurança hídrica tem que tornado cada vez mais diverso, indo além até mesmo dos aspectos de quantidade e acessibilidade para populações humanas, adotando aspectos como a qualidade da água, saúde humana e proteção dos ecossistemas (COOK; BAKKER, 2011).

Ademais das diferentes perspectivas adotadas, muitas vezes o que se nota é um emprego do termo de forma despolitizada, principalmente nos debates impulsionados por organizações multilaterais, como o Banco Mundial, ignorando as condicionantes políticas e sociais da segurança hídrica. Nesses debates muitas vezes o que aparece como pano de fundo são ideias neomalthusianas, que colocam a causa da insegurança hídrica na superpopulação e principalmente na população mais pobre (BRYANT, 1998; PEET; WATTS, 2002; LOFTUS, 2015).

Ainda que as pesquisas sobre água no campo da ecologia política raramente utilizem o termo, o campo oferece contribuições valiosas para discussão sobre a segurança hídrica de uma forma mais complexa, com metodologias e reflexões teóricas que possibilitam compreender as relações de poder que estão presentes na produção e reprodução da insegurança hídrica. Nesse sentido, o presente artigo pretender apresentar algumas das discussões do campo da ecologia política que permitem essa visão mais complexa, considerando que a segurança hídrica envolve diversos aspectos do acesso à água, que por sua vez é mediado por relações de poder, que envolvem questões políticas, econômicas, sociais e culturais que se desenvolvem ao longo do tempo e de diferentes escalas (SWYNGEDOWN, 2006).

\section{METODOLOGIA}

O presente artigo se vale do levantamento bibliográfico acerca dos temas de Segurança Hídrica e Ecologia Política da água, com o objetivo de recolher informações relevantes acerca da temática, que possibilitaram construir uma reflexão acerca das contribuições que as construções teóricas e metodológicas do campo da Ecologia Política trazem para o debate da segurança hídrica.

\section{O CAMPO ECOLOGIA POLÍtiCA: CONTRIbUiÇÕes PARA A SEGURANÇA HÍDRICA}

Nos anos de 1990 surge um novo contexto de crescente preocupação com as questões ambientais nos diversos setores da sociedade (sociedade civil, academia e Estado), frente a um contexto de transformações políticas e econômicas e pela apreensão por parte da sociedade da crise ecológica. Essa preocupação resultou majoritariamente em correntes que tentavam compatibilizar a conservação ambiental com o modo de produção e consumo vigente (BRYANT, 1998; PEET; WATTS, 2002).

Essas correntes ganham força principalmente pelo contexto da época, em que se via a queda do socialismo e em contrapartida o avanço do neoliberalismo, onde a crise ambiental passava a ser vista 
em termos globais, acompanhada do ressurgimento das ideias malthusianas alimentadas por um discurso de gestão dos recursos e governança ambiental global. Com isso, a sustentabilidade e o desenvolvimento sustentável se tornaram termos frequentes na literatura e na retórica de grandes organizações, como o Banco Mundial (PEET; WATTS, 2002). O que se vê nessas correntes é a tentativa de compatibilizar dois aspectos que em sua essência não podem ser compatibilizados: a acumulação capitalista e a conservação ambiental.

A partir dessa constatação houve um maior interesse pelo desenvolvimento de um campo que trouxesse a compreensão sobre os obstáculos políticos e econômicos para uma mudança significativa, como resposta a essa agenda de pesquisa ambiental dominante que se colocava como apolítica (BRYANT, 1998; ROBBINS, 2012). Nesse sentido, a principal contribuição do campo da ecologia política é o entendimento de que a política é parte central para compreender as interações entre sociedade e natureza (BRYANT, 1998). Os problemas ambientais, entretanto, não são decorrentes de uma falha política, mas a manifestação das forças econômicas e políticas associadas ao espalhamento do capitalismo, e só podem, portanto, ser superados por meio de uma mudança radical nas estruturas políticas e econômicas, desde a escala local até a global (BRYANT, 1997).

Sendo assim, de acordo com a abordagem do campo da ecologia política para entender os problemas ambientais, é preciso entender como se dão as relações desiguais de poder e de que modo elas influenciam nas relações entre sociedade e natureza, restringindo ou habilitando determinados atores frente um ao outro em relação ao ambiente físico. Portanto, a ideia de que a relação entre os atores e a natureza é condicionada por relações de poder é central na ecologia política (BRYANT, 1997).

Para tal o campo emprega uma variedade de teorias e metodologias, recebendo a contribuição de diversas correntes teóricas críticas como o materialismo verde, teoria pós-colonial, economia política urbana, feminismo, entre outros (ROBBINS, 2012). A ecologia política em si não se trata de uma teoria ou uma metodologia, mas um campo de abordagem onde essas diferentes teorias e métodos se encontram ao empírico para explicar como e com qual motivação os humanos estão transformando a natureza (BATTERBURY, 2015).

As pesquisas que se situam nesse campo buscam ir além de observar apenas os problemas ambientais, investigando por meio de teorias e métodos diversos, as raízes desses problemas, que perpassam questões políticas, econômicas e sociais. A direção, segundo Robbins (2012), é buscar as causas e não apenas os sintomas (ROBBINS, 2012; BRYANT, 1998).

Um dos temas de pesquisa comuns no campo da ecologia política diz respeito ao acesso ou exclusão a recursos, entre eles a água. Nesse sentido, se entende que o acesso ou a exclusão é mediado por relações de poder (ROBBINS, 2012; SWYNGEDOUW, 2006). Isso porque, salvo raras exceções, usualmente a questão de acesso à água em qualidade e quantidade adequadas trata-se mais de uma questão distributiva e de governança do recurso, do que uma questão de escassez natural, técnica e/ou de crescimento demográfico (SWYNGEDOUW, 2006; BAKKER, 2012).

A perspectiva da ecologia política para tratar sobre a água e sua circulação trabalha com o entendimento de que a há uma correlação entre as transformações do ciclo hidrológico nas diferentes escalas e as relações de poder social, político, econômico e cultural, ou seja, uma relação hidro-social (SWYNGEDOUW, 2009).

Isso parte do conceito de metabolismo, que tem base nos escritos de Marx, e que entende que o ambiente é uma combinação de construções sócio-físicas que são historicamente produzidas, tanto em termo de conteúdo social, como de qualidade física do ambiente. Desse modo, o mundo é compreendido como sendo parte natural, parte social, parte técnico e parte cultural, sem fronteiras definidas entre tais partes. E é por meio de uma análise geográfica e histórica desses processos que podemos entender as relações de poder pelas quais o ambiente é produzido, e que, por sua vez, transforma as relações de poder (SWYNGEDOUW, KAÏKA, CASTRO, 2002). 
Os processos de mudança desse metabolismo não são neutros socialmente, nem ecologicamente. Como resultado, certas mudanças beneficiam determinados grupos sociais ao mesmo tempo em que afetam negativamente outros grupos com menos poder. Essas relações de poder pelas quais os processos metabólicos acontecem merecem especial atenção, pois é por meio dessas geometrias de poder em que se decide em última instância quem terá acesso, quem irá controlar e quais serão os excluídos, moldando as configurações sociais e políticas do ambiente em que vivemos (SWYNGEDOUW, KAÏKA, CASTRO, 2002).

Esse entendimento nos leva ao fato de que a água, sendo um recurso natural, tende a fluir para o poder, e usualmente grupos que detém poder social detém também o acesso e o controle da água. Do mesmo modo, o controle da água gera poder, o que reforça e estende esse controle, desse modo, o controle da natureza e o poder social se constituem de forma mútua (SWYNGEDOUW, 2006).

A ecologia política tem trabalhado com uma abordagem relacional e dialética em relação à água, e evoluído essa abordagem ao longo do tempo. Em suma, trabalhar com a abordagem relacional e dialética permite entender que as coisas se tornam o que são em relação a outras coisas, em um processo mútuo de transformações. Nesse sentido o conceito de ciclo hidrossocial tem sido amplamente utilizado no campo da ecologia política, e se diferencia do conceito de ciclo hidrológico que tem como foco os fluxos da água na hidrosfera; o ciclo hidrossocial olha também para os componentes sociais presentes nesses fluxos, observando o modo dialético com que água e sociedade interagem (LINTON; BUDDS, 2014). O ciclo hidrossocial é definido de acordo com a formulação de Linton e Budds (2014) como: “[...] um processo sócio-natural onde a água e a sociedade se fazem e refazem uma à outra ao longo do espaço e tempo." (LINTON; BUDDS, 2014).

Essa abordagem do ciclo hidrossocial tem importantes contribuições para a discussão da segurança hídrica. O autor Alex Loftus (2015) pontua que é necessário entender o ciclo hidrossocial mais do que apenas o ciclo hidrológico, o que requer um esforço para entender historicamente e espacialmente as relações entre a sociedade e a água. Segundo o autor, olhar a segurança hídrica pela lente do ciclo hidrossocial é importante, pois a crise global a qual a segurança hídrica está tentando responder é resultado de uma visão moderna da água, que reduziu está a uma dimensão meramente quantitativa, sendo preciso, portanto, desafiá-la, trazendo uma visão da água por meio da sua relação evolutiva com a sociedade através do tempo e do espaço (LOFTUS, 2015).

Loftus (2015) também chama atenção para o fato de que acima de tudo não se pode pensar na segurança hídrica de forma despolitizada, pois isso ignora os interesses envolvidos na reprodução da insegurança hídrica e o entendimento sobre as relações entre a população, economia e Estado. Além disso, a despolitização acaba retirando o componente político da distribuição da água, fazendo com que essa questão seja reduzida a apenas um problema resultante de questões de ordem natural e/ou que pode ser resolvido apenas por meio de soluções tecnológicas (LOFTUS, 2015).

Nesse mesmo sentido, Swyngedouw (2013) coloca que a falta de água é socialmente e políticamente construída, sendo expressão da pobreza e da exclusão de populações marginalizadas que não possuem poder na esfera política e econômica. Essas relações desiguais de poder estão expressas no ciclo hidrossocial, ou seja, colaborando com o que foi colocado por Loftus, (2015), que não se pode pensar na resolução de um problema que tem raiz social e política sem levar em conta a análise dessas relações (LOFTUS, 2015; SWYNGEDOUW, 2013).

\section{CONCLUSÕES}

Ainda que as pesquisas sobre água no campo da ecologia política ainda utilizem pouco o termo "segurança hídrica", as análises e abordagens do campo, como o ciclo hidrossocial, têm diversas contribuições uma vez que exploram a desigualdades no acesso a água, com um enfoque nos modos como as relações sociais de poder combinados com fatores materiais e ecológicos moldam a forma 
como a água é distribuída. Essas pesquisas do campo nos ajudam a entender que a insegurança hídrica, vivenciada pelos grupos minoritários, não é resultado de uma explosão demográfica ou uma escassez natural, mas é na verdade produzida e reproduzida socialmente e politicamente (TRUELOVE, 2019).

Essa construção teórica proveniente do campo da ecologia política, nos permite entender a segurança hídrica a partir de uma visão focada na garantia do acesso da população a água em qualidade e quantidade, considerando que o acesso à água não está restrito apenas a questões técnicas, mas faz parte das relações entre água e sociedade, onde a falta de acesso não está relacionada apenas à falta física da água, mas também é uma expressão da desigualdade.

Sendo assim, o campo da ecologia política, principalmente por meio do conceito do ciclo hidrossocial, tem importantes contribuições para um melhor entendimento das condicionantes da insegurança hídrica, pois enxerga essa questão de forma mais complexa, considerando os diversos fatores que condicionam o acesso a água, e que vão além de um determinismo ambiental ou interpretações neomalthusianas. Tal entendimento é importante, pois permite compreender os obstáculos que existem para a equidade no acesso a água, que como visto, passam pela necessidade de uma mudança radical nas estruturas políticas e econômicas de poder, desde a escala local.

\section{REFERENCIAS}

BAKKER, Karen. Water security: Research challenges and opportunities. Science, v. 337, n. 6097, p. 914-915, 2012.

BATTERBURY, S. Doing polítical ecology inside and outside the academy. In: BRYANT, Raymond. The International Handbook of Polítical Ecology. Cheltenham, UK: Edward Elgar Publishing, 2015.

BRYANT, R. L. Beyond the impasse: The power of polítical ecology in Third World environmental research. Area, v. 29, n. 1, p. 5-19, 1997.

BRYANT, R. L. Power, knowledge and polítical ecology in the third world: A review. Progress in Physical Geography, v. 22, n. 1, p. 79-94, 1998.

COOK, C.; BAKKER, K. Water security: Debating an emerging paradigm. Global Environmental Change, v. 22, n. 1, p. 94-102, 2012.

GLOBAL WATER PARTNERSHIP. Towards Water Security: A Framework for Action. Stockholm: [s.n.], 2000.

LINTON, J.; BUDDS, J. The hydrosocial cycle: Defining and mobilizing a relational-dialectical approach to water. Geoforum, v. 57, p. 170-180, 2014.

LOFTUS, Alex. Water (in)security: securing the right to water. The Geographical Journal, v. 181, n. 4, p. 350-356, 2015 
PEET, R.; WATTS, M. Liberation Ecology: Development, sustainability, and environment in an age of market triumphalism. In: PEET, R.; WATTS, M. Liberation Ecologies: Environment, development, social movements. Londres: Routledge. 2002. Cap. 1. Pag. 1-45.

SHIVA, I. Water Wars. Cambridge: South End Press. 2002.

SWYNGEDOUW, E. Power, Water and Money: Exploring the Nexus. UN Water, p. 1-85, 2006. SWYNGEDOUW, Erik. UN Water Report 2012: Depoliticizing Water. Development and Change, v. 44, n. 3, p. 823-835, 2013.

SWYNGEDOUW, Erik. The Polítical Economy and Polítical Ecology of the Hydro-Social Cycle View project. Journal of Contemporary Water Research, 2009.

TRUELOVE, Yaffa. Rethinking water insecurity, inequality and infrastructure through an embodied urban polítical ecology. Wiley Interdisciplinary Reviews: Water, v. 6, n. 3, p. e1342, 2019. 